\title{
Atypical presentation of eosinophilic granulomatosis - typical presentation in an ageing population?
}

\author{
Catriona Reddin ${ }^{1}$, Kevin Kitt ${ }^{1}$, Bernadette Lynch², Eamon Mulkerrin ${ }^{1}$ \\ ${ }^{1}$ Department of Geriatric medicine, Galway University Hospital, Galway, Ireland; ${ }^{2}$ Department of \\ Rheumatology, Galway University Hospital, Galway, Ireland
}

Severe systemic vasculitis presenting in an 80 year old female involving a presentation with recurrent pyrexia, eosinophilia, mononeuritis multiplex against a background of late onset asthma, consistent with eosinophilic vasculitis with angiitis is described. Despite appropriate management with resolution of systemic symptoms, she failed to return to baseline functionality. Systemic vasculitis is rare in this population cohort, but it is important to consider as it is treatable albeit with a guarded outlook for full neurological recovery.

Key words: Churg Strauss syndrome, ageing, vasculitis

\section{INTRODUCTION}

Received: December 8, 2019

Accepted: December 12, 2019

\section{Correspondence}

Catriona Reddin

Department of Geriatric medicine, Galway University Hospital, Newcastle Road, Galway, Ireland

E-mail: catriona.reddin@hse.ie

\section{Conflict of interest}

The Authors declare no conflict of interest

How to cite this article: Reddin C, Kitt K, Lynch B, et al. Atypical presentation of eosinophilic granulomatosis - typical presentation in an ageing population? Journal of Gerontology and Geriatrics 2020;68:194-6. https://doi.org/10.36150/2499-6564-411

C Copyright by Società Italiana di Gerontologia e Geriatria (SIGG)

\section{(c) (1) () (}

\section{OPEN ACCESS}

This is an open access article distributed in accordance with the CC-BY-NC-ND (Creative Commons Attribution-NonCommercial-NoDerivatives 4.0 International) license. The article can be used by giving appropriate credit and mentioning the license, but only for non-commercial purposes and only in the original version. For further information: https://creativecommons.org/licenses/by-nc-nd/4.0/deed.en
Eosinophilic granulomatosis with polyangiitis or Churg-Strauss syndrome (CSS) is a primary eosinophilic vasculitis of small to medium blood vessels. It is a multisystem disorder characterised by asthma, sinus pathology, neuropathy and eosinophilia ${ }^{1}$. The median age of presentation is $48^{2}$. The WHO report that by the year 2050 there will be over 1.5 billion people over the age of 65 years old ${ }^{3}$. Based on demographic trends, a broad differential should be maintained in all age groups.

\section{CASE REPORT}

An 80 year old female patient was referred by her general practitioner (GP) after a one week history of recurrent fevers and dysuria. She also reported a one week history of burning bilateral leg pain.

During inpatient admission, she developed acute weakness of her left foot. Examination demonstrated MRC grade 1/5 power in dorsiflexion, with plantarflexion preserved, consistent with a left-sided foot drop. On the next day, power of dorsiflexion and plantarflexion was reduced to $1 / 5$, with absent ankle reflexes and diminished knee reflexes. There was reduced light touch sensation bilaterally in L4, L5 and S1 dermatomes, proprioceptive loss to the ankle joint and loss of vibration sense to the costal margin. She demonstrated sensory ataxia.

Her medical history included recent onset asthma, gastritis, anaemia, benign thyroid adenoma and atrial fibrillation. Asthma was diagnosed 2 years earlier and resulted in two hospital admissions for exacerbations during the previous year. She reported a five month history of generalised fatigue. She lived with her husband in a two-storey house, and she was independent 
Table I. Serial Eosinophil Counts during eosinophilic phase of illness and response to definitive treatment.

\begin{tabular}{|l|c|c|c|c|c|c|c|c|}
\hline & $\begin{array}{c}\text { 1 month pre } \\
\text { admission }\end{array}$ & Day 1 & Day 4 & Day 8 & Day 10 & Day 15 & $\begin{array}{c}\text { Day 17 } \\
\text { (post methylprednisolone) }\end{array}$ & Day 22 \\
\hline $\begin{array}{l}\text { Eosinophil } \\
\text { count }\end{array}$ & 1.35 & 6.63 & 10.39 & 22.38 & 21.94 & 22.7 & 3.6 & 0.9 \\
\hline
\end{tabular}

in all activities of daily living. A lifelong non-smoker, she had never consumed alcohol and was very active in her community.

Urine culture grew an Escherichia coli organism sensitive to co-amoxiclav therapy and she was treated with appropriate antibiotics but swinging pyrexia persisted. During the second week of admission she developed a prominent eosinophilia (Tab. I). An auto-immune screen returned strongly positive for C-ANCA, with an MPO titre of $97 \mathrm{IU} / \mathrm{ml}$. Cytoplasmic ANCA pattern is usually associated with antibodies directed against PR3 however it is less commonly associated with MPO antibodies. A bone marrow aspirate showed mildly hypercellular marrow, with no evidence of malignancy.

A sural nerve biopsy surprisingly showed no evidence of vasculitis. Nerve conduction studies showed absent response from peripheral nerves in lower limbs with relatively normal findings in upper limbs, consistent with mononeuritis multiplex. Given the overall clinical context, her deterioration likely reflected active ANCAassociated vasculitic nerve ischaemia secondary to eosinophilic granulomatosis with polyangiitis.

She was treated with high dose intravenous steroids, a five day course of intravenous immunoglobulin and cyclophosphamide $10 \mathrm{mg} / \mathrm{kg}$. Her pyrexia and systemic symptoms resolved. She received sensory and gait reeducation and lower limb strengthening exercises. Footup splints were required, and graded stepping practice was introduced. Her maintenance therapy includes azathioprine and low dose glucocorticoids. She demonstrated improvement in leg power and partial return of muscle strength. However, after 7 months treatment, she can only mobilises short distances with the aid of a frame and continues to feel "imprisoned by her feet".

\section{DISCUSSION}

CSS can be divided into three stages; prodromal, eosinophilic and vasculitic ${ }^{4}$. This lady had recent onset asthma (prodromal phase) and she reported constitutional symptoms for five months prior to this presentation. She developed an acute eosinophilia followed by neurological symptoms. Differential diagnosis included leukaemia (AML), lymphoma, parasitic diseases and hypereosinophilic syndromes.

Studies on ANCA vasculitities in the older person have shown that while presentation may be similar across age groups, older patients tend to have higher frequencies of renal involvement and less frequent cutaneous involvement. Older patients have a higher mortality rate. The five-factor score is used to guide prognosis. Of note age over 65 years of age is an independent poor prognostic indicator for CSS. In patients with a five factor score of 1 or more, the recommendation is to commence cyclophosphamide or rituximab ${ }^{4}$. Maintenance therapy includes agents such as azathioprine or methotrexate ${ }^{5}$.

This case underscores the importance of considering vasculitis as a differential diagnosis in all age groups. Vasculitis in the older person can be challenging to diagnose and treat and it is often compounded by comorbidities and polypharmacy ${ }^{6}$. While systemic symptoms usually respond, long term recovery from neurological manifestations is less likely.

\section{LEARNING POINTS FOR CLINICIANS}

- Vasculitis is a rare cause of deterioration associated with neuropathy in an older person, and will likely more frequently be encountered given ageing demographic trends.

- When eosinophilia coincides with overt signs of neuropathy, eosinophilic granulomatosis with vasculitis(CSS) should be considered.

- While systemic symptoms usually respond, long term recovery from neurological manifestations is less likely in older patents.

\section{COMPLIANCE WITH ETHICAL STANDARDS}

Written informed consent for publication of their clinical details and/or clinical images was obtained from the patient.

\section{References}

1 Jennette JC, Falk RJ, Bacon PA, et al. 2012 Revised International Chapel Hill Consensus Conference Nomenclature of Vasculitides. Arthritis Rheum 2013;65:1-11. https://doi. org/10.1002/art.37715

2 Mouthon L, Dunogue B, Guillevin L. Diagnosis and classification of eosinophilic granulomatosis with polyangiitis (formerly named Churg-Strauss syndrome). J 
Autoimmun2014;48-49:99-103. https://doi.org/10.1016/j. jaut.2014.01.018

3 World Health Organisation. Global health and aging 2011 (Available from: https://www.who.int/news-room/factsheets/detail/ageing-and-health).

4 Gioffredi A, Maritati F, Oliva E, et al. Eosinophilic granulomatosis with polyangiitis: an overview. Front Immunology 2014;5:549. https://doi.org/10.3389/fimmu.2014.00549
5 Bosch X, Guilabert A, Espinosa G, et al. Treatment of antineutrophil cytoplasmic antibody - associated vasculitis: a systematic review. JAMA 2007;298:655-69. https://doi. org/ 10.1001/jama.298.6.655

6 Langford CA. Vasculitis in the geriatric population. Rheum Dis Clin North Am 2007;33:177-95. https://doi. org/10.1016/j.cger.2005.02.011 